\title{
An activity theory approach toward teacher professional development at scale (TPD@Scale): A case study of a teacher learning center in Indonesia
}

\author{
Cher Ping Lim ${ }^{1}$. Juliana ${ }^{2} \cdot$ Min Liang ${ }^{3}$
}

Received: 14 June 2020 / Revised: 21 October 2020 / Accepted: 22 October 2020 / Published online: 19 November 2020

(c) The Author(s) 2020

\begin{abstract}
Continuous teacher professional development (TPD) ensures that teachers have the capacity to continually plan and implement quality teaching and learning that supports students in achieving their expected program/course learning outcomes. However, teachers' access to quality TPD is a challenge due to geographical limitations, gender, special needs, marginalized communities, and the government's policies, or lack of policies, regarding teachers. There are tensions between quality and equity, and cost implications that may hinder the scaling up of quality TPD programs. This paper adopts an activity theory approach to examine how a teacher learning center (TLC) in a regency of Indonesia enhances teachers' access to quality TPD. The findings reveal that teachers learn in the TLC through different TPD activities. Information and Communication Technologies (ICT) are found to mediate the professional learning activities, learning resources, learning support, and assessments in the TLC. Furthermore, three key stakeholders-the local government, teacher working groups, and school principals_-play significant roles in supporting teachers' professional learning in the TLC.
\end{abstract}

Keywords Teacher professional development (TPD) · TPD@Scale · ICT · Activity theory · Teacher learning center · Indonesia

\section{Introduction}

Education in developing countries faces significant challenges in achieving the United Nation's Sustainable Development Goal 4 of ensuring access to quality education and lifelong learning for all ( $\mathrm{Ra}$ et al. 2016). The lack of competencies among teachers may be one of the factors that compromises students' access to quality education. In Indonesia, a South-East Asian country with one of the largest and most diverse teacher workforces in the world, Indonesian

Cher Ping Lim

clim@eduhk.hk

1 Chair Professor of Learning Technologies and Innovation, Faculty of Education and Human Development, The Education University of Hong Kong, Hong Kong SAR, China

2 Program Development Manager, School Development Outreach, Putera Sampoerna Foundation, Jakarta, Indonesia

3 e-Learning Specialist, Faculty of Education and Human Development, The Education University of Hong Kong, Hong Kong SAR, China teachers' average score in the national Teacher Competency Test was 66.94 out of a maximum of 100 (Aghnia and Sandy 2018). This low score reflects the lack of competencies among Indonesian teachers and the need for better teacher competency at school and regency levels (The World Bank 2018). The Organisation for Economic Co-operation and Development (OECD) claims that teacher quality is the single most important school-level variable influencing student achievement and has a significant impact on the quality of national education (OECD 2018). The quality of teachers is one of the factors that have led to about $75 \%$ of schools in Indonesia not meeting the national standards of education.

To ensure quality teaching and learning, teachers must be qualified and provided with opportunities for continuous professional development to develop the expected competencies regarding content knowledge, pedagogical knowledge, and professional knowledge (UNESCO 2020). However, teachers in Indonesia have limited access to professional development opportunities due to three issues, as identified by Supriatna (2011). First, the national government does not have a mechanism for continuous teacher professional development (TPD) after teachers have been awarded their 
certifications. Second, TPD at the provincial level has little capacity to engage teachers on a large scale. Third, the Subject Teacher Working Group, Musyawarah Guru Mata Pelajaran (MGMP), which is a professional community for subject teachers at the district level (in Indonesia, districts are located in regencies, and regencies are located in provinces), has not been able to function as an effective professional support system to provide quality TPD. On the one hand, MGMP encounters difficulties in implementing TPD due to its unstructured programs. On the other hand, transport is a challenge for teachers in rural and remote areas in terms of participating in MGMP's face-to-face TPD (Supriatna 2011).

To address these TPD challenges, the Putera Sampoerna Foundation - School Development Outreach (PSF-SDO) initiated the Teacher Learning Center (TLC) program. TLCs aim to provide teachers at each level in the regency with greater access to quality and cost-effective TPD opportunities by combining face-to-face and online professional learning. The aim is to eventually create a sustainable teacher professional learning community. To date, PSF-SDO has built and supported 10 TLCs in Indonesia (TPD@ Scale Indonesia 2019). PSF-SDO is part of the TPD@ Scale Coalition for the Global South (TPD@ Scale hereafter), which was initiated by the Digital Learning for Development (DL4D) network to promote collaboration among different stakeholders engaged in TPD. These stakeholders could belong to the following groups: the Ministry of Education (MoE) from countries in the Global South, international/national/regional organizations and agencies, non-governmental organizations, and educational and technology institutions. Through collaboration, research, and support in implementation, TPD@ Scale aims to help countries to enhance and scale up quality, equitable, and efficient information and communication technologies (ICT)-mediated TPD based on individual local contexts.

However, the access to and scaling up of quality TPD has different challenges such as ICT infrastructure and tools, geography, and sociocultural factors. To address these challenges, there is a need to examine the complexities and contexts within the TPD program. Adopting an activity theory approach, this paper examines how a TLC can enhance teachers' access to quality professional development in an Indonesian regency. Both qualitative and quantitative data were collected and analyzed to examine teachers' professional learning in the ICT-mediated TPD program, the roles of key stakeholders, and how ICT is used for implementing TPD.

\section{Making sense of the learning design of TPD@Scale}

To ensure quality and inclusive education and lifelong learning for all, TPD must be of high quality, equitable, and efficient. To ensure quality, TPD has to sustainably focus on pedagogy, content, and active learning, and it must support collaboration according to the teachers' contexts. Modeling of effective practice, coaching and expert support, and feedback provision has to be part of the TPD process (Darling-Hammond et al. 2017). The content and process of TPD have to support teachers' learning to achieve the expected professional learning outcomes. In terms of equity, barriers to TPD such as access to ICT, geographical location, gender, and socioeconomic-political factors have to be addressed (UNESCO 2015). Efficiency refers to the correlation between the input of time and resources for the TPD, and the output/deliverables for the TPD stakeholders (Laurillard et al. 2018). To address the tensions between these three key characteristics of TPD, TPD@Scale adopts an ICT-mediated and context-focused approach to blend face-to-face with online learning, modalities, resources, and activities appropriate for teachers living and working in diverse and under-resourced contexts across the Global South (TPD@ Scale Coalition 2019). Massive Open Online Courses (MOOCs), open courseware, and Learning Management Systems (LMS) have the potential to enhance teachers' engagement and professional learning outcomes on a larger scale and in a more cost-effective way than traditional faceto-face approaches.

To ensure quality ICT-mediated TPD, a learning design framework (Herrington et al. 2003; Oliver 2001) is adopted to focus on the professional learning activities, resources, and support of the ICT-mediated TPD. The TPD activities are designed based on the expected professional learning outcomes that are driven by learning tasks, resources, and support. Assessment, which is at the intersection of tasks, resources, and support, guides teachers in monitoring and managing their own professional learning. At the same time, the TPD activities are situated in different contexts, for example, individual TPD program, school, district, regional, and national education system, etc. Therefore, the design of the TPD@Scale program must take into account the sociocultural context. This is expressed as circles in Fig. 1. The challenges and issues of TPD may stem from collective, societal dimensions rather than individual ones. The theoretical framework in this paper needs to provide a holistic lens to examine the nexus of sociocultural factors in different levels of contexts, that is TPD@ Scale program level, school level, and local education system level.

\section{Teacher learning centers as regard TPD@Scale}

In the last decade, Indonesia has significantly improved access to quality education, including the implementation of decentralization to allow agencies more autonomy on education policies and practices, the allocation of $20 \%$ of the national budget for education, and the practice of a 
Fig. 1 The learning design framework of TPD@Scale program in different levels of contexts

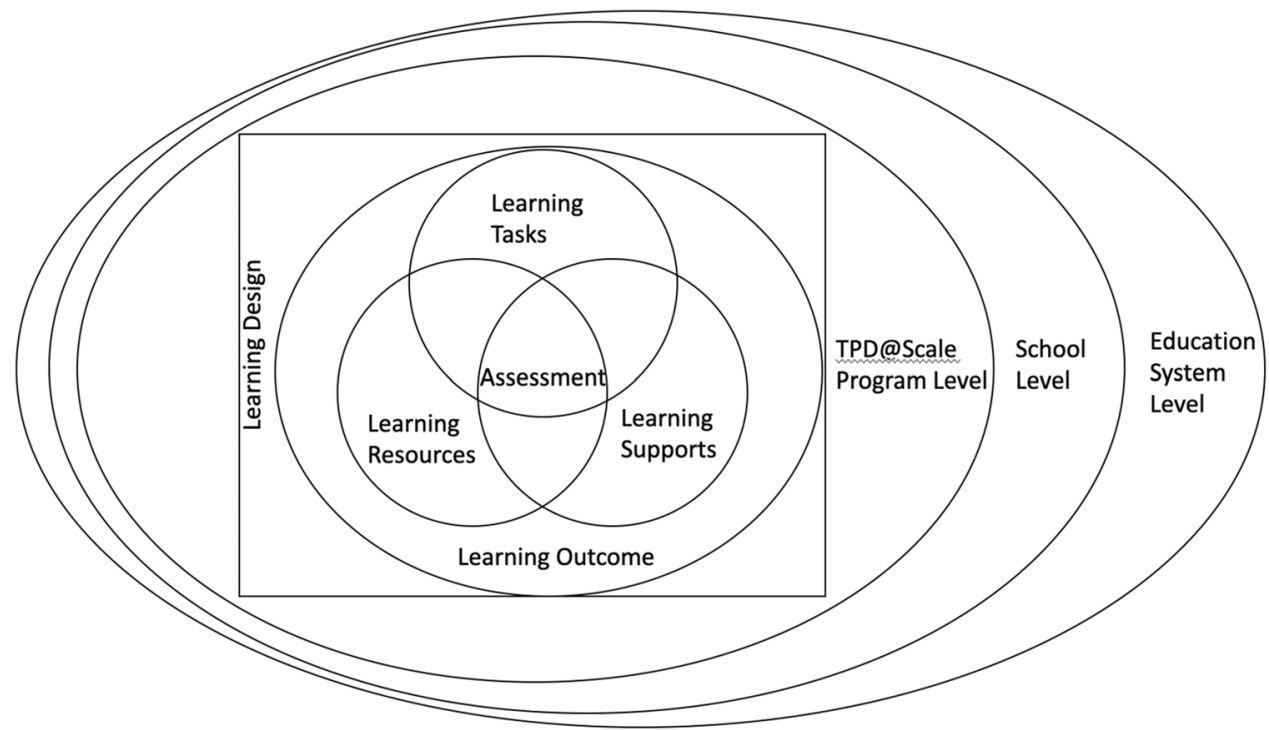

teacher certification policy to improve teacher quality (The World Bank 2019). The decentralized education system, where schools are managed at the regency level, allows the local government more flexibility to cater to the diverse needs of students in various sociocultural contexts. Such flexibility is relevant to TPD.

TLCs are established at the regency level as systematic and structured independent learning organizations supervised by the local government and managed by selected teachers from schools in the regency. TLCs aim to provide teachers with quality and cost-effective TPD opportunities to build their capacity for quality teaching and learning. To build a community of practice that provides TPD opportunities, a TLC facilitates collaborative partnership and cultivates local leadership. The programs are tailored according to the teachers' needs in the community. The role of the TLCs is to develop contextualized TPD programs and activities with access to learning facilities and resources, to monitor and evaluate TPD programs, and to build and maintain strategic partnerships with the local government, schools, and private and public organizations. To identify the teachers' professional learning needs and their preference as regards learning delivery, the TLCs conduct regular surveys before developing annual TPD programs. TLCs reposition TPD as a way of tackling the professional learning needs of teachers to enhance their learning outcomes and transform their teaching and learning practices. The TPD programs include pedagogy, technology, and subject content across different levels. They are delivered through (i) face-to-face, (ii) online (synchronous learning through video conferencing tools and asynchronous learning for implementation in the classroom through WhatsApp/Telegram), and (iii) blended modes.
A TLC consists of master teachers (MTs) and TLC coordinators to serve teachers within the regency. TLC coordinators are selected teachers who manage the center and coordinate TPD activities, and MTs are subject facilitators who develop TPD modules, deliver TPD activities, and evaluate the process. TLCs are managed by the heads together with coordinators to ensure the TLC governance system is in place and this is overseen by the local education authority who endorses policies developed by the TLC. Such partnerships ensure the smooth running of the center and support MTs to plan and implement TPD activities based on the local context. Once teachers complete the TPD course, the TLC awards them a TPD certificate and credit points endorsed by the local government. The credit points teachers earn will contribute to their promotion in accordance with the civil servants' promotion framework of the MoE and their own school's guidelines.

To scale up teachers' access to TPD, ICT has the potential to mediate the access, quality, and efficiency of the TPD program. How ICT tools mediate teachers' TPD activities, such as through Zoom, WhatsApp, and Schoology, may be influenced by the resources they have, the activities the TLC designs and conducts, and the support from their community where different stakeholders interact and collaborate. Likewise, teachers' learning and their professional learning outcomes from the TPD activities by the TLC are also influenced by the ICT-facilitated learning tasks, resources, and support and the various stakeholders involved.

\section{Activity theory}

As TPD@Scale programs are context-dependent, it is critical to understand how TPD is designed and implemented 
in local contexts. Activity theory is adopted in this paper to examine the connections between different elements in the TPD program.

Activity theory first focuses on the concept of the toolmediated action of an individual (Vygotsky 1980), and then the structure of human collective activity (Leont'ev 1978). It suggests that human learning emerges from activities and emphasizes both the historical development of ideas, and the active and constructive role of humans. It provides a sociocultural and socio-historical perspective when examining human thinking, learning, and activities. The theory was further developed by Engeström (1987) to bring in the concept of activity system analysis. He considers the activity in an activity system as an object-oriented and tool-mediated collective effort. He thinks that human minds are situated in a context in which power relations and rules impact on individuals' actions (Engeström 1987). Figure 2 demonstrates the elements of an activity in an activity system.

In the context of ICT-mediated TPD, the object may be a learning (or assessment) task that is aligned with the expected professional learning outcome. The subject may be the teacher who engages in the professional learning activities mediated by ICT and non-ICT tools. The community consists of different teachers engaged in the professional learning task within the TPD environment. The rules are "the explicit and implicit regulations, norms and conventions that constrain actions and interactions within the activity system" (Engeström 1993, p. 67), and "specify and regulate the expected correct procedures and acceptable interactions among the participants" (Cole and Engeström 1993, p. 7) in the community. The division of labor within the community provides the mechanisms for teachers to complete the learning task to achieve the professional learning outcomes. Tasks, responsibilities, and power are continuously negotiated among teachers in this community. Within and between activity systems, the communication aspect of

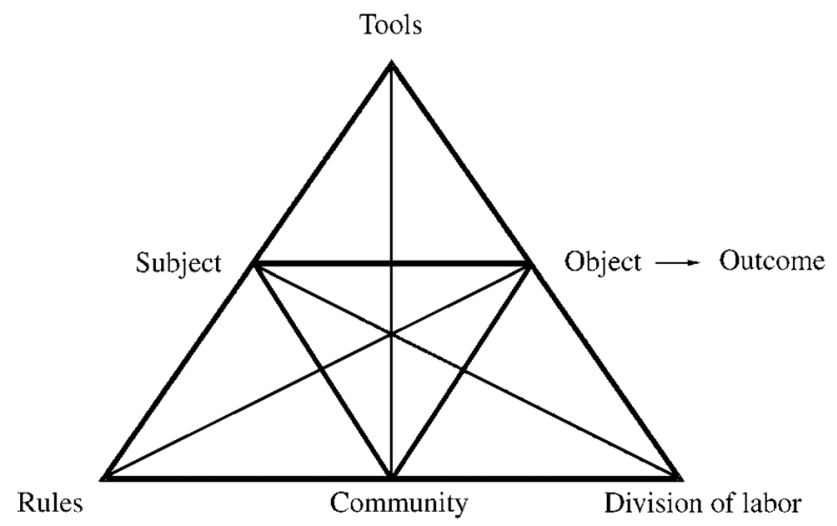

Fig. 2 Activity theory framework (Engeström 1987, p. 78) learning is highlighted, in which knowledge is shared and co-constructed by individuals (Hardman 2008).

Activity systems are subject to change, which are driven by contradictions that may occur within and between systems (Engeström 1987). Contradictions could be understood as resistance and barriers to achieving the outcomes. There are two main types of contradictions in the activity systems, internal contradictions and external contradictions (Engeström 1992). These contradictions may lead to "disturbance and breakdown" (Hasu and Engeström 2000, p. 65 ) in the design, development, implementation, and evaluation of teaching and learning. Hence, apart from studying human activities per se, it is necessary to examine the context in which these activities are situated to identify contradictions within and between activity systems. This will improve our understanding of the process of transformation within an activity system and how different systems interact with, influence, and even transform each other over time (Engeström 1987).

\section{An activity theory perspective of the TLC as regards TPD@Scale}

Although studying the activity system of the teachers participating in TPD programs may provide insights into how they learn within their ICT-mediated TPD@ Scale program, there is a need for a more holistic understanding of how teachers learn in the sociocultural settings of the program, school, and regency. Consequently, it is necessary to study the TPD program as an activity system situated within other activity systems that represent different levels of sociocultural contexts. Previous studies have demonstrated how the activity in a specific context is affected by other activity systems (Lim and Hang 2003; Hirst and Vadeboncoeur 2006; Smardon 2004). These multiple contexts in which a TPD program operates afford different, complementary but also conflicting tools, rules, and patterns of social interaction, which may lead to different levels of quality, equity, and efficiency in the TPD@Scale programs. Therefore, a three-level activity system approach (Fig. 3) is proposed in this paper to frame the case study of a TLC in Indonesia and to guide data collection and analysis.

The first level in the center is the TPD@Scale program (i.e., TLC level), the second level is the school (i.e., school level), and the third and outermost level is the local education system (i.e., regency level). These three levels of activity systems are mediated by ICT and non-ICT tools that are adopted to facilitate TPD activities, and strategies to achieve the expected professional learning outcomes of the TPD programs. Subjects and communities in the activity systems are different but interrelated. Teachers at TLC level are supported by school leaders and administrators, who are supported by local education officials and policymakers. The 


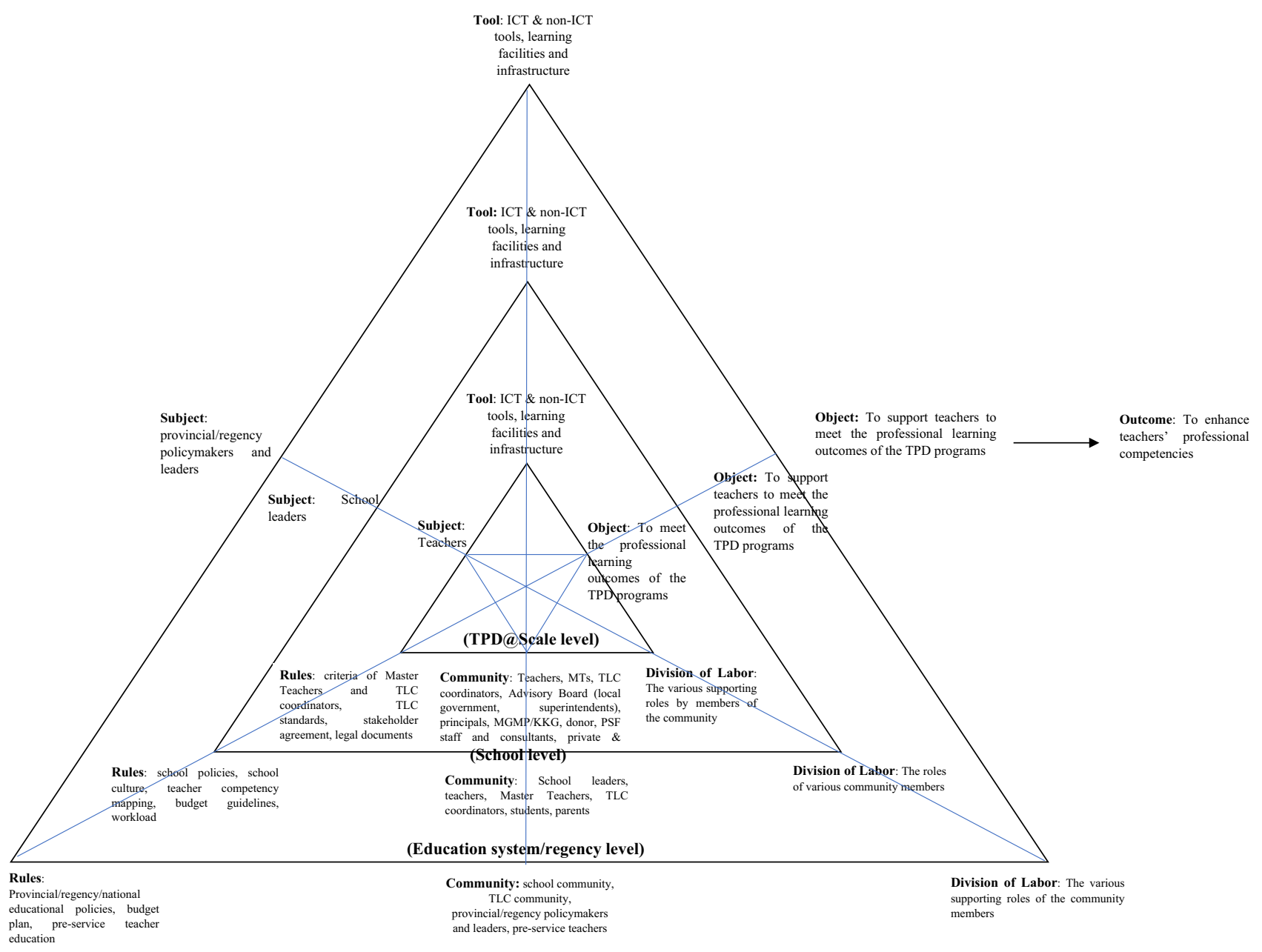

Fig. 3 A three-level activity system of the TPD@ Scale program

TLC-level community is closely connected to the TLC's stakeholders from school-level and regency-level communities that consist of teachers, MTs, TPD@Scale program management leaders, parents, students, school leaders and education officials, and policymakers. The TLC-level object is to meet the expected professional learning outcomes of the TPD programs, and the objects of the other two levels are to facilitate and support teachers in TLC-based and/ or school-based TPD to meet these expected learning outcomes. The three levels of activity systems work toward the same outcomes, that is, to enhance teachers' professional competencies that will benefit the subjects and communities at all three levels.

This approach could not only help researchers to analyze the TPD@Scale activities and the interplay of activities mediated by ICT or non-ICT tools, but could also help to identify the facilitating factors and contradictions in different contexts that could potentially impact on the quality, equity, and efficiency of the TPD@ Scale program.
The elements within and across the activity systems are driven by the shared outcome. In terms of the quality of the TPD@Scale program, ICT-mediated TPD activities could enable teachers to actively collaborate, reflect, and support one another. The tasks involved, such as designing learning modules, and administrative and logistic support, have to be clearly communicated and divided among its members. These collaborative efforts may build a supportive community that is informed and guided by rules and policies. In terms of equitable access in the TPD@ Scale context, ICT as a tool in the activity system provides access to as many teachers as possible. School policies on the curriculum, the teaching schedule, and the selection criteria of MTs influence teachers' availability and motivation to participate in the TPD program. Key stakeholders from schools and the policies of the local education bureaus support and contribute to the achievement of the shared outcomes. 


\section{Contradictions within and between the activity systems of TPD@Scale}

The three-level activity system approach shows the relationships and interactions of different elements within and between the activity systems. As the activity systems at different levels operate in different sociocultural contexts, designing, developing, implementing, and evaluating the TPD@Scale program is a complex process. They are characterized by contradictions within and between the activity systems that may affect the quality, equity, and efficiency of the TPD@Scale program. Such contradictions are developmentally significant and manifested in the form of tensions that are involved in achieving the expected professional learning outcomes. It is important to identify and address these contradictions to ensure the equity, quality, and efficiency of the TPD@Scale program.

A primary internal contradiction occurs when an element of an activity system moves away from its original intention. For example, a teacher may consider attending TPD program as the object rather than focusing on the development of his/ her professional competencies. This may lead to tensions between the intended object and the actual object. Secondary internal contradictions are caused by tensions between different elements within an activity system (Engeström 1992). For example, when a teacher applies an ICT-mediated inquiry-based teaching approach he/she has learned from TPD program to the class, his/her previous perception of the teacher's role as a knowledge transmitter may contradict his/her role as a learning facilitator and the students' role as active constructors of knowledge. That is, the teacher has changed his/her teaching strategies and tools, but his/her pedagogical perception and the division of labor remains unchanged. Such internal contradictions between the subject and the division of labor, and between the division of labor and the tool, may lead to a loss of learning autonomy and agency for the students carrying out the inquiry, adversely affecting the students' learning engagement and outcomes.

An external contradiction can occur between the elements of different activity systems. One external contradiction could be tension between the central activity and a culturally advanced form of activity. For example, in certain schools, the conventional rules mediating the arrangement of teaching and learning may hinder the development and implementation of a TPD program. Even if the TPD program is formally implemented, teachers' professional learning may be restricted due to the school timetable. That is, teachers may not have the time to engage in the TPD program. Other external contradictions may be caused by school leaders' reluctance to release MTs (school-level activity system) to conduct TPD activities at the TLC (TLC-level system).

Although contradictions within and between activity systems may lead to tensions and conflicts in the activity systems, they often drive transformations of the systems. The contradictions also provide a better understanding of breakdowns in relationships (Demiraslan and Usluel 2008; Murphy and Rodriguez-Manzanares 2008). Therefore, in this study, analyzing these contradictions could help the TLC to better address the tensions and conflicts at each level of activity system and also between the different levels so that teachers can enhance their professional competencies.

This paper examines how a TLC enhances teachers' access to quality professional development in an Indonesian regency. The factors supporting and hindering teachers' professional learning are also examined. The three research questions are as follows:

1. How do teachers learn in a TLC and in schools to meet the expected professional learning outcomes?

2. What are the roles of the key stakeholders of the TLC?

3. What is the role of ICT in mediating the TPD activities of the TLC?

\section{Research design and methods}

\section{Context}

The study was conducted in a TLC in Kudus, one of the regencies in Central Java, Indonesia. There are about 6540 teachers (Indonesian Ministry of Education and Culture 2019a) from 1566 primary and high schools in the regency (Indonesian Ministry of Education and Culture 2019b) and about 906 teachers (Indonesian Ministry of Education and Culture 2019c) in 40 pre-schools (Indonesian Ministry of Education and Culture 2019d). Due to the decentralized education system, a regency only manages and supervises pre-school, primary, and middle schools, whereas, a province also manages high schools and provides support to strengthen the regional educational services. The TPD program in the TLC in Kudus is aimed at teachers from pre-school to senior high school. TLC Kudus is led by a head of the TLC, and is supported by 48 MTs and 11 TLC coordinators. Since it was first established, the MTs have developed 18 TPD modules based on the results of the needs and situation analysis. The TLC has reached 6333 teachers through face-to-face and online TPD in 2 years.

\section{Data collection and analysis}

The study adopted a mixed methods approach to collect and analyze both qualitative and quantitative data with the guidance of research questions. Mixed methods not only provide a more comprehensive account of the TLC TPD program, but also support the researchers in addressing the research questions from an activity theory perspective. The 
qualitative data collected by the focus group interviews could provide an understanding of the sociocultural factors and local context for the TLC TPD program, and the quantitative data collected by the survey serve as indicators of the TPD outcomes. Hence, such an approach provides a deeper understanding of the TPD program, and the triangulation of these contextual data captures the efficiency of implementation in the TLC.

Focus group interviews were conducted with seven teachers, 10 TLC coordinators, 10 MTs, four school principals, six representatives of the local government of Kudus, and two PSF facilitators of the TLCs. Within each group, the teachers, TLC coordinators, MTs, and principals were from different schools. However, across groups, some of them were from the same school. The schools selected were at different educational levels (primary and secondary schools) and were in different geographical locations (urban and rural). The selection of the teachers, coordinators, MTs, and principals was based on gender, years of experience, and teaching subject. The local government representatives and PSF facilitators were selected according to their role in the organization, and their years of experience working in the education sector. The interviews examined how the different elements in the activity system interact with one another. The interview questions were constructed based on the activity systems at the TLC, school, and local education system level, and included participants' background information, the role of ICT in the TPD program, the support and roles of teachers, MTs, TLC coordinators, principals, and local government representatives, the rules, the community, and the object and outcomes of the TPD program.

The survey for teachers was administered to examine how ICT mediated their teaching in schools and learning at the TLC. The questions in this survey included ICT usage in learning activities, resources, support, and assessment, the intensity of using ICT, how ICT tools mediate their learning activities in the TPD program, and how ICT tools mediate the assessments. There were 106 respondents in this survey. A purposive sampling method was applied to ensure representatives of each level (pre-school, primary, and secondary). In total, 73 pre-school teachers, 29 primary school teachers, and four secondary school teachers completed the survey. Both the interviews and the survey were conducted in the local language, Bahasa Indonesia, then transcribed and translated by the researchers into English for data analysis. The demographic of the respondents is depicted in Table 1 below.

The data analysis mainly focused on the interview transcripts, field notes from the interview, and the result of the survey driven by the research questions. For the interview data, a thematic analysis (Terry et al. 2017) approach was adopted. Under the guidance of the research questions, the researchers separately read the transcripts from interviews
Table 1 The demographics of the respondents

\begin{tabular}{ll}
\hline Respondents' demography & Respondents' demographics \\
\hline Education background & $93 \%$ Bachelor's degree \\
& $4 \%$ Master's degree \\
& $3 \%$ Diploma \\
& $83 \%$ Female \\
Gender & $17 \%$ Male \\
Teachers' employment status & $37 \%$ Civil Servants of Public Schools \\
& $31 \%$ Private School teachers \\
& $25 \%$ Contract Teachers of Public \\
& Schools \\
& $8 \%$ Non-Civil Servants \\
& $69 \%$ Early childhood level \\
Teaching level & $27 \%$ Primary school level \\
& $3 \%$ Junior high school level \\
& $1 \%$ Senior high school level
\end{tabular}

with teachers, school leaders, and local government officials. Initially, some key ideas related to the research questions were identified from the transcripts, and were then developed into a set of categories/codes. The researchers identified the key words from the interview data that could form the themes of the findings. The researchers then discussed and categorized the findings into key themes that closely related to the research questions. The quantitative data were analyzed following a univariate descriptive statistics procedure. Before analysis, data cleaning and coding of responses were carried out. In this study, the quantitative findings were descriptive in nature and focused on the teachers' responses to technology usage in training and the role of the key stakeholders (TLC, teacher participants, principals, and local government) in supporting TPD.

\section{Key findings}

\section{Teachers learn through various TPD activities in the TLC and in school to meet the professional learning outcomes}

TPD in the TLC is defined as any formal and informal activities that are made available through internal and external expertise in the form of workshops/coaching, sharing good practice, and collaboration between teachers across the school that develop a teacher's knowledge, skills, and disposition. The TLC has conducted 74 TPD programs for 6 , 333 teachers in Kudus Regency. At the beginning of the TLC program, a need and situation analysis was conducted to understand teachers' needs as regard TPD. Based on the analysis, the MTs developed several TPD modules for the TLCs related to assessment, teaching strategies and 
approaches, ICT use in teaching, digital learning media, lesson plan development, classroom action research, and basic literacy. The professional learning activities during these programs included group discussions, hands-on activities/ experiential learning, problem-solving (i.e., case studies), reading group sessions, and classroom practices to achieve the professional learning outcomes. The activities usually consisted of $30 \%$ lecturing and $70 \%$ collaborative work to provide teachers with active professional learning experiences that were different from traditional TPD.

The survey administered to 106 teachers' participants showed that $55 \%$ of them found experiential learning the most effective, whereas $34 \%$ perceived that reading group sessions and group discussions worked best for them. The rest thought that case studies supported them in making sense of and contextualizing their own teaching. The activities in the TLC were conducted both face-to-face and online. The face-to-face activities usually took place during the workshops, while the online activities focused more on the support given to teacher participants on their classroom practices through WhatsApp. A total of $69 \%$ stated that they found technical guidance was the most instrumental learning support and 31\% argued that modeling and providing further explanation were the support they needed during classroom practice. All teachers in the survey stated that the TLC programs were useful for their professional learning and their classroom teaching and learning practice.

The TLC set common ground rules for teachers to evaluate their own professional learning, for example, steps and templates for action research, assessment rubrics, and reflection guides. The MTs administered pre- and post-tests to examine teachers' comprehension of the topics covered in the TPD module. Additionally, they monitored teachers' practices in the classroom, and the teachers also shared how they applied what they learned with other teachers within their TPD group. One MT in Kudus explained:

After the TPD, I asked my teachers to send me photos and videos of them applying ICT in their own class. I want to see them apply what they have learnt, and I also want them to share with their fellow teachers.

However, teachers' professional learning outcomes are not evaluated at the system level. The head of the regency education bureau said that the bureau did not have the evaluation system and tools to assess the impact of TPD on teachers' professional learning. Instead, the impacts of TPD were measured by teachers' attendance and completion rates, and the number of TPD programs implemented in a year as compared to the number that was planned.

The TLC was evaluated from three perspectives: activities of the TLC (number of TPD activities conducted by the TLC, the number of teachers involved, the number of partners the TLC has engaged, the TLC's capacity to self-fund and sustain), impacts on teachers' professional learning (teachers' teaching and learning competencies, teachers' feedback), and impacts on teachers' practices (classroom practices, impacts of practices on student learning). Although evaluating the impacts of TLC on teacher practices was a major challenge due to the constraints of human resources, budget, and time, the school principals and government officials spoke favorably about their observed impacts, as explained by the head of the regency education bureau:

The MTs will only organize TPD that is most needed by the teachers. Teachers are more likely to implement what they have learnt at the TLC. I can see that many teachers have tried to adopt what they have learnt at the TLC for their students in class.

However, contradictions appeared within the TLC activity system at the TPD@Scale program level. First, the MTs and TLC coordinators found that time management was the biggest issue, as they had to split the time that they spent at the TLC and their time teaching in schools. Second, the demands for TPD at regency level have been growing exponentially and the MTs and TLC coordinators, who were selected teachers from schools, might lack the necessary competencies to manage the TLC effectively and efficiently. Third, Kudus has its own culture and norms that affect communication and decision-making. The contradictions challenged the implementation of the TPD activities in the TLC but, at the same time, pushed the professional development of the MTs and TLC coordinators. To address these contradictions, peer support and a conducive work environment were important to support them as either an MT or a TLC coordinator.

The teachers have indeed learned in various ways and were supported by various resources to meet their professional learning outcomes. Schools, in particular, provided computers and Internet connections to support teachers in both their teaching and professional learning. The regency government allocated a certain budget to fund the TLC and provided teachers with a teaching syllabus, and allocated funds in teacher working groups to run their TPD programs. However, there was still no specific and structured evaluation system and tools to assess the effectiveness of TPD. To tackle the evaluation issue, the TLC has to take over the monitoring functions and examine the impacts of TPD on teacher competencies and classroom implementation.

\section{Local government, teacher working groups, and school principals are important key stakeholders of the TLC}

In this study, the roles of three key stakeholders in TLC Kudus were examined. They were the local government, teacher working groups, and school principals. 


\section{Local (regency) government}

The local government, as the owner of the TLC, played a critical role. For the construction of TLC Kudus, which was funded and managed by the private sector, the local government issued a construction license and a decree for its establishment. A total of $66 \%$ of MTs and TLC Coordinators stated that the local government provided administrative support in terms of issuing TPD certificates and consent letters for teachers, $16 \%$ of MTs and TLC Coordinators acknowledged the supporting role of the local government's strategic direction (i.e., TPD policies and TLC acknowledgment), and the rest confirmed that the local government provided them with support in terms of infrastructure, such as the provision of learning facilities and buildings. The extent of the local government support was reflected by the large proportion of participating teachers, almost two-thirds, in the TLC programs that were sponsored by the local government.

The local government also allocated funding for TPD in the TLC and encouraged the TLC to run a self-funded TPD program for interested teachers and/or schools. The head of the local education bureau pointed out that the bureau also encouraged the collaboration of teacher working groups and the TLC to meet teachers' TPD needs in the regency.

\section{Teacher working groups MGMP/KKG/IGTKI}

There are different teacher working groups in Indonesia that engage in TPD:

- Musyawarah Guru Mata Pelajaran (MGMP) or Subject Teachers' Working Group is for middle and high school teachers to work collaboratively in professional learning communities to build their capacity for quality teaching and learning.

- Kelompok Kerja Guru (KKG) or Teachers' Cluster Working Group is for primary school teachers in the same cluster schools to engage in professional development.

- Ikatan Guru Taman Kanak Kanak Indonesia (IGTKI) or Indonesian Pre-School Teachers Organization serves preschool teachers from the same cluster schools in their professional development.

These teacher working groups were the other key stakeholders of the TLC. With encouragement from the local government, MGMP, KKG, and IGTKI partnered with the TLC to plan and implement TPD for teachers in the regency. This partnership, formalized by the Memorandum of Understanding (MoU), facilitated

- the dissemination and publicizing of, and registration for, the TLC activities,
- the conduct of the annual teachers' professional learning needs analysis, and

- the organization of customized TPD activities for teachers during the MGMP, KKG, and IGTKI regular meetings by the MTs of the TLC.

The partnership was reflected in the TPD collaborations between the TLC and MGMP, KKG, and IGTKI that represented more than a quarter of the 74 training sessions conducted in the TLC. However, in the interviews, the middle school MTs raised their concerns regarding acknowledgment. They said that they struggled to be acknowledged by their peers as "legitimate" TPD facilitators as their peers preferred officially (by the government) certified instructors or university professors. The MTs from pre-schools and primary schools did not encounter such a challenge as they felt that they were "valued" and "respected" for their quality rather than their legitimacy.

\section{School principals}

School principals had a significant role and responsibility for the TLC because the MTs and TLC coordinators were selected teachers from their schools. With the support from the principals, the MTs and TLC coordinators could then engage in planning, coordinating, and implementing the TPD activities for teachers within their regency. The principals worked with the MTs and TLC coordinators to ensure a replacement to cover their classes when there was a schedule conflict for the TPD activities at the TLC. The principals also arranged for an Internet connection, computers, and projectors for the TPD activities to be conducted in their schools, and have been supportive in sending their teachers to the TLC or other schools for professional learning. In support of this, $62 \%$ of MTs stated that their principals have provided administrative support, $20 \%$ said that they obtain pedagogical support, $14 \%$ perceived that their principals were always available for strategic support, and $4 \%$ confirmed the principals supported them with the provision of learning tools. To support TPD in schools, $86 \%$ of the principals confirmed that they have developed TPD plans and policies.

Although the principals were all supportive of the TLC and the TPD activities, the principals did have some concerns, especially as regards the loss of some of their best teachers to the TLC. One of the principals mentioned that:

My teacher is one of the TLC's Master Teachers who leads training sessions once a month during the school day. I support her $100 \%$ but her classes miss her excellent teaching each month. I hope that she can always be with us in school both as a teacher for our students and for our teachers (for professional development). 
There were also different levels of funding allocation by schools in the regency for TPD. Private schools tend to allocate more funding for TPD than public schools. One of the principals from a private school mentioned that "it is important that my teachers are equipped with the latest skills and knowledge to enhance their students' learning." From the interviews, some public school teachers mentioned that they could not attend some TPD activities hosted by the TLC because they had no access to funding and have to rely on the TPD activities organized by the local government.

Based on the interviews with the representatives of the local government, teachers, and school principals, TLC Kudus has developed connections among its different stakeholders and enhanced the communication and collaboration between schools, the MGMP/KKG/IGTKI, and the local government in the regency. The division of labor among the stakeholders in these interactions was crucial for the functioning of TLC Kudus. There were contradictions identified within and between activity systems of the TLC, schools, and local government. The lack of acknowledgment for some middle school MTs by their peers and the lack of empathy for the MTs by their school principals might lead to the MTs becoming disengaged from the TLC. At the same time, the funding allocation for teachers from some public schools might adversely affect TPD participation. To address these contradictions, the support from school principals and colleagues was critical. Apart from the availability of laptops, Internet, and teaching-learning resources, school principals have to support their teachers who are also MTs and TLC coordinators. They have to arrange for substitute teachers to allow the MTs and TLC coordinators to plan and implement the TPD activities.

To support the TLC in providing teachers with access to quality TPD in the regency, the local government has to implement policies that facilitate the establishment and sustainability of the TLC. This includes the provision of infrastructure and resources, and the allocation of its budget for the TLC operations. The local government also has to monitor the effectiveness of the TLC and promote it as the learning center for all teachers in the regency. The MGMP, KKG, and IGTKI have to collaborate with the TLC to gather and analyze data regarding teachers' professional learning needs through surveys, and facilitate the access of the MTs to their regular MGMP/KKG/IGTKI meeting for the PD of their teachers. At the school level, school principals have to encourage and fund their teachers to participate in the TPD activities of the TLC, and free the MTs and TLC coordinators to plan and implement these TPD activities.

\section{ICT mediates the functions of the TLC}

In this paper, the TPD@Scale learning design situated in three levels of contexts together with the activity theory perspective was adopted to examine how learning activities, resources, support, and assessment were mediated by ICT in TLC Kudus to provide teachers in the regency with access to quality professional learning.

\section{ICT for learning activities}

ICT played a significant role in mediating TPD activities in TLC Kudus. WhatsApp/Telegram acted as mediums for information updates, consultations with MTs, and postlearning activities. Schoology, the TLC's adopted LMS, was used for assignment and completed task submissions, and as a teaching and learning resource repository. However, Schoology has not been fully explored as the TLC deemed that WhatsApp and Telegram served the existing communication, sharing, mentoring, and peer learning needs. In the medium term, the TLC intended to use the online discussion and e-class functions on the LMS.

The MTs and TLC coordinators conducted selected TPD sessions online and shared topic-based resources by WhatsApp/Telegram as it supported group messages, photo, video, and document sharing to large groups of teachers who were participating in the TPD activities. The online sessions were either facilitated by the MTs or guest speakers including university teachers, industry experts, and MTs from other regencies. The online sessions were highly valued by both the MTs and teachers who found them interactive and affordable (all teachers participating in the TPD activities owned a smart phone that could access the Internet) and catered for their personal schedule.

In the online sessions facilitated by the MTs, the participating teachers were engaged in the professional learning. They actively participated in the group discussions and learning tasks. The MTs usually began the sessions by proposing an open question or issue (for example, planning for an ICT-enabled science lesson or managing a mixed ability class) for the teachers to discuss. The teachers were scaffolded as they discussed the question or issue and the MTs guided them toward achieving the expected professional learning outcomes of the session.

The follow-up activities after the TPD modules were usually conducted through WhatsApp. The teachers were encouraged to apply what they had learned in their own school and classroom, share their practices with other teachers (for example, a short video of a learning activity in the classroom), and discuss challenges that might emerge during classroom implementation. The MTs were expected to form WhatsApp groups, post resources, and lead the discussions. However, the MTs and TLC coordinators who were interviewed expressed that they preferred regular face-to-face meetings for the follow-up activities because "meeting in person is part of the culture of East Java to show politeness and avoid misunderstanding." 
In the survey, all the teachers acknowledged the effectiveness of using ICT in professional learning activities. A total of $74 \%$ of the teachers accessed their emails, WhatsApp, Telegram, and Facebook for their professional learning every day, and the rest utilized the apps once a week. ICT added value to their TPD because it provided more flexibility for those who have a hectic school and family schedule, hence, providing them with better access to TPD. They also found learning in an ICT-enabled environment more "stimulating and engaging," leading to quality professional learning (extracts from the focus group interview with teachers). One of the teachers shared that:

I don't have to travel to the training venue to participate in the workshop. I can access the online class at an agreed convenient time. Besides, I think it is interactive and the training topic could be applied in my classroom. I never imagined that doing training online would be this much fun.

\section{ICT for learning resources}

ICT mediated the TPD activities in the TLC and in the schools. The teachers had access to ICT facilities in their school and in the TLC to engage in their professional learning. Although the head of the local education government bureau said that all teachers could access to the resources provided by the regencies/provinces/national government, the website of the local government was not updated regularly, and it lacked an online library for teachers in the regency to access to teaching and learning resources (including professional learning resources). Based on the survey, $38 \%$ of the teachers used ICT for sharing resources, $35 \%$ used ICT for discussions, and about $27 \%$ used ICT for repository purposes. All of the teachers accessed the professional learning resources through WhatsApp/Telegram and only less than $30 \%$ of the teachers logged into Schoology to access the resources. As a result, some of the MTs did not use Schoology for their TPD modules.

\section{ICT for learning support}

ICT to support teachers' professional learning includes ICTmediated consultations and scaffolding of online learning activities by the MTs. It also involves the provision of laptops/computers, projectors, and Internet access by the local government, foundations (e.g., the Yayasan Sekolah Foundation), and private organizations in the schools. Although most of the teachers have been introduced to the use of ICT for teaching and learning, one of the teachers in the focus group interview who was approaching his retirement complained that he was initially "lost when doing online learning." He said that it was his fellow teachers in the TPD module who "teach me how to use WhatsApp and other computer things."

TLC Kudus is in a building equipped with a wireless Internet connection and the necessary hardware (computers, servers, data projectors, printers, and scanners) for the MTs and TLC coordinators to plan for and implement TPD activities for teachers in the regency. The infrastructure and hardware provisions in the private sector provided the necessary conditions for the TLC team to support the professional learning of the teachers. PSF-SDO worked together with the local government to build the capacity of the TLC team. This included the development of the instructional design and pedagogical competencies of the MTs, and the development of the leadership and management competencies of the TLC coordinators. As an effort to support the TLC, the local government gave their endorsement for blended TPD activities through the TLC and the sharing of information regarding TPD activities through social media. Facebook was the platform used to share and monitor the implementation of the TLC TPD activities.

\section{ICT for learning assessments}

As the MoE has instructed schools to explore the use of online assessment and e-school management systems, the MTs in the TLC have been administering online assessments and sharing lesson plans of their TPD sessions online. They used Google Forms to conduct a post-module survey and pre- and post-tests, and used Google Docs for teachers to work collaboratively on group tasks and assignments. Three of the teachers in the interview reported that using Google Docs for group assignments was "practical and convenient" as it enabled them to "contribute to the group work anytime and anywhere." In the teacher survey, 53\% of the teachers claimed that they have used ICT in their assessment practices with their students in schools. One teacher in the interview explained:

I only started using Google Forms, Quiz and other user-friendly applications for assessing my students' learning after I had experienced it as a learner in the TLC. It opened up my eyes to what is possible with technology and how it can improve the assessment process and learning.

ICT has indeed enabled TLC Kudus to provide the teachers in the regency with access to quality TPD. For learning activities and resources, the TLC used WhatsApp/Telegram to communicate, disseminate, and share information, resources and practices, conduct online sessions, implement post-professional learning activities, facilitate group work on assessment tasks, and enable assignment submission. By using these two mobile applications, geographical constraints were significantly reduced, the sharing of resources 
and practices was enhanced, and professional discussions and learning were facilitated after the TPD module. For learning support, the MTs and TLC coordinators provided mentorship and support for teachers anywhere and anytime. The local government was connected by social media to the MTs and TLC coordinators to monitor the TPD activities of the TLC. For learning assessments, all teachers who have participated in the TPD modules have had experiences in ICT-enabled assessments. However, contradictions within and between the activity systems might hinder the implementation of the TPD module in the TLC. First, aging teachers who might not have much experience in using ICT might be excluded from TPD if they could not use ICT for their own professional learning. Second, Internet access has been limited in some areas of Kudus. Third, teachers in Kudus preferred face-to-face meetings due to the local culture. Fourth, the regulation of the blended learning credit hours issued by the local government might restrict the TLC from conducting full online TPD.

\section{Discussions and conclusion}

Based on the activity theory perspective, teachers as the subjects in the TLC activity system have engaged in the TPD activities organized by TLC Kudus to meet the expected professional learning outcomes. The ground rules were made explicit to the teachers and pre- and post-tests were conducted to examine the impact of the TPD activities on teachers' competencies. After the TPD module, the teachers' classroom implementation was monitored and shared to examine the impact of and enhance their professional learning. However, the evaluation of the teachers' professional learning outcomes by the local government has focused on teachers' PD attendance and the number of TPD activities attended. There was no evaluation system, criteria, or instrument in place to comprehensively evaluate teachers' professional learning outcomes and the effectiveness of the TPD. Without an appropriate evaluation system, criteria, or instruments, the content, and processes of TPD could not be fully examined and improved in a sustainable way.

The local government of Kudus, teaching working groups, and school principals have been playing important roles in supporting the TPD activities and operations of the TLC. The local government at the regency level formulated, endorsed, and supervised the establishment of the TLC and the implementation of the TPD activities. With the encouragement of the local government, teacher working groups MGMP/KKG/IGTKI assisted in the promotion of the TPD activities, the conduct of the needs and situation analysis, and the conduct of TPD sessions. The school principals at the school level are pivotal in supporting the TPD activities. First, the principals have to formulate school policies that would support the MTs and TLC coordinators; these rules have to be applied to allow these MTs and coordinators to manage, design, and implement the TPD activities of the TLC. Second, school principals also supported the TLC by opening up the school facilities for the TPD activities. However, some principals were worried that the MTs and coordinators were not spending enough time in the school supporting students in their learning. This concern might negatively impact on the school principals' support of the TPD activities. Besides, the different funding practices of public and private schools might impact teachers' PD participation, with those from private schools less likely to participate in TPD.

From the perspective of ICT mediation, ICT was the tool in the activity system that enabled the TPD activities. Instant message applications such as WhatsApp and Telegram enabled teachers to share information and participate in online TPD sessions and post-TPD activities. However, face-to-face discussions/meetings were still the preferred mode of communication among the MTs and TLC coordinators due to the local culture in Kudus. The LMS Schoology supported the teachers to submit assignments and download teaching and learning resources. ICT-enabled assessments drew upon Google Suite for survey, collaborative work, and quizzes; most of these assessments were summative in nature. ICTenabled formative assessment tools such as e-portfolios were not part of the TPD activities.

The discussions so far have highlighted the challenges that TLC Kudus faced as it tried to transform the professional development practices and policies in the regency. The TLC has empowered the stakeholders (local government, MGMP/KKG/IGTKI, schools, and teachers) to work collaboratively together to provide access to quality TPD for the teachers. The improvement in professional learning outcomes has to be measured by pre- and post-tests and teacher surveys. These could be complemented by lesson observations conducted by teachers who have completed their professional development. The TLC also enabled stakeholders to work toward a common goal of the activity system, that is, to enable teachers to meet the professional learning outcomes of the TPD activities so as to enhance their teaching and learning competencies. In addition, the TLC has been building relationships among teachers in the community to share and collaborate, providing equal opportunities for teachers' continuous professional development, and strengthening the teacher professional learning network. Selected MTs and TLC coordinators might integrate ICT into some of their TPD sessions, and support teachers to use ICT to support their own professional learning.

Contradictions were found within and between the activity systems. By examining and addressing these contradictions, the findings will provide lessons learnt for other TLCs or TPD activities. First, internal contradictions 
were found between the age of the teachers and the ICT used in the TPD activities, and the local culture and ICT used in the TLC. Although the TLC has used ICT for its TPD, it was a challenge for older teachers as they preferred to have face-to-face TPD instead of blended learning. The local culture in Kudus highlighted the importance of faceto-face discussions to show politeness. Issues of being acknowledged, time management, and the workload of the MTs, TLC coordinators, and teachers could also lead to internal and external contradictions. For example, the teachers' teaching load might restrict their involvement in TPD activities. External contradictions might come from the local government's professional development system and evaluation mechanism. The implementation of TPD activities may be ineffective if there is no monitoring and evaluation mechanism. Also, the leadership of the school and government influences policies that may have an impact on teachers' professional learning.

To address these contradictions, policies have to be formulated to support the TPD activities in the TLC to ensure their sustainability. The issue of a decree for MTs and TLC coordinators could enable them to gain more trust as local TPD facilitators among their peers. Moreover, the availability of the TPD budget in the regency development plan might provide more professional learning opportunities for contracted teachers. Lastly, regular supervision by the local government on the TLC is necessary for creating a conducive professional learning environment in schools and in the regency.

There are two key limitations of this study: (1) the adaptation of activity theory, and (2) the availability of participants for this study. In the case of the TPD@Scale program, a group of teachers is considered as the subject, whereas activity theory originally focused on the individual as a subject. This group of teachers may not share the same object in the activity system. This study, therefore, identifies the common object of the professional learning outcomes of the TPD activities for enhancing teachers' professional competencies as the object in each of the three levels of the activity systems. The representation of the sample of the target population is limited due to the lack of access to key stakeholders. There is a need for future research to increase the sample size and improve the representativeness of the sample.

Acknowledgments We thank the TPD@ Scale Coalition for the Global South (TPD@Scale) that has supported this study. The study is funded by the International Development Research Centre (Canada) and the Putera Sampoerna Foundation (Indonesia).

Funding This study was funded by the TPD@Scale Coalition for the Global South (TPD@Scale), and does not involve any conflict of interest on the part of the authors. While the authors are not able to share the raw data to the public, peer researchers are welcomed to discuss issues related to this paper by emailing the correspondence. The raw data and interview transcripts are stored in password-protected computers owned by and accessible only to the research team of this study.

Open Access This article is licensed under a Creative Commons Attribution 4.0 International License, which permits use, sharing, adaptation, distribution and reproduction in any medium or format, as long as you give appropriate credit to the original author(s) and the source, provide a link to the Creative Commons licence, and indicate if changes were made. The images or other third party material in this article are included in the article's Creative Commons licence, unless indicated otherwise in a credit line to the material. If material is not included in the article's Creative Commons licence and your intended use is not permitted by statutory regulation or exceeds the permitted use, you will need to obtain permission directly from the copyright holder. To view a copy of this licence, visit http://creativecommons.org/licenses/by/4.0/.

\section{References}

Aghnia, A., \& Sandy, N. (2018). Nilai Kompetensi Guru di Indonesia. https://beritagar.id/. [in Indonesian].

Cole, M., \& Engeström, Y. (1993). A cultural-historical approach to distributed cognition. In Distributed cognitions: Psychological and educational considerations (pp. 1-46). New York: Cambridge University Press.

Darling-Hammond, L., Hyler, M. E., \& Gardner, M. (2017). Effective teacher professional development. https://learningpolicyinstitute. org/sites/default/files/product-files/Effective_Teacher_Profession al_Development_REPORT.pdf.

Demiraslan, Y., \& Usluel, Y. K. (2008). ICT integration processes in Turkish schools: Using activity theory to study issues and contradictions. Australasian Journal of Educational Technology, 24(4), $458-474$.

Engeström, Y. (1987). Learning by expanding an activity - Theoretic approach to developmental research. Helsinki: Orienta-Konsultit Oy.

Engeström, Y. (1992). Interactive expertise: Studies in distributed working intelligence. Research Bulletin 83. Department of Education, University of Helsinki, Bulevardi 18, SF-00120 Helsinki, Finland.

Engeström, Y. (1993). Developmental studies of work as a testbench of activity theory: The case of primary care medical practice. In Understanding practice: Perspectives on activity and context (pp. 64-103). Cambridge: Cambridge University Press.

Hardman, J. (2008). Researching pedagogy: An activity theory approach. Journal of Education, 45(1), 65-95.

Hasu, M., \& Engeström, Y. (2000). Measurement in action: An activity-theoretical perspective on producer-user interaction. International Journal of Human-Computer Studies, 53(1), 61-89.

Herrington, J., Oliver, R., \& Reeves, C. (2003). Patterns of engagement in authentic online learning environments. Australian Journal of Educational Technology, 19(1), 59-71.

Hirst, E., \& Vadeboncoeur, J. A. (2006). Patrolling the borders of otherness: Dis/placed identity positions for teachers and students in schooled spaces. Mind, Culture, and Activity, 13(3), 205-227.

Indonesian Ministry of Education and Culture. (2019a). https://dapo. dikdasmen.kemdikbud.go.id/guru/2/031900. [in Indonesian].

Indonesian Ministry of Education and Culture. (2019b). https://refer ensi.data.kemdikbud.go.id/index11.php?kode=031900\&level $=2$. [in Indonesian].

Indonesian Ministry of Education and Culture. (2019c). https://manaj emen.paud-dikmas.kemdikbud.go.id/Rekap/PAUD-TK-Statu s-Kepegawaian?semesterId $=20192 \&$ kodeWilayah $=030000$. [in Indonesian]. 
Indonesian Ministry of Education and Culture. (2019d). https://refer ensi.data.kemdikbud.go.id/index21.php?level $=3 \&$ kode $=03190$ $2 \& \mathrm{id}=1$. [in Indonesian].

Laurillard, D., Kennedy, E., \& Wang, T. (2018). How could digital learning at scale address the issue of equity in education? In Learning at scale for the global south. Quezon City: Foundation for Information Technology Education and Development.

Leont'ev, A. (1978). Activity, consciousness and personality. Englewood Cliffs: Prentice Hall.

Lim, C. P., \& Hang, D. (2003). An activity theory approach to research of ICT integration in Singapore schools. Computers \& Education, 41(1), 49-63.

Murphy, E., \& Rodriguez-Manzanares, M. A. (2008). Using activity theory and its principle of contradictions to guide research in educational technology. Australasian Journal of Educational Technology, 24(4), 442-457.

OECD. (2018). PISA 2015 result in focus. https://www.oecd.org/pisa/ pisa-2015-results-in-focus.pdf.

Oliver, R. (2001). Seeking best practice in online learning: Flexible learning toolboxes in the Australian VET sector. Australian Journal of Educational Technology, 17(2), 204-222.

Ra, S., Chin, B., \& Lim, C. P. (2016). A holistic approach towards Information and Communication Technology (ICT) for addressing education challenges in Asia and the Pacific. Educational Media International, 53(2), 69-84.

Smardon, R. (2004). Streetwise science: Toward a theory of the code of the classroom. Mind, Culture, and Activity, 11(3), 201-223.

Supriatna, A. (2011). Indonesia's issues and challenges on teacher professional development. CICE Series, 4(2), 29-42.

Terry, G., Hayfield, N., Clarke, V., \& Braun, V. (2017). Thematic analysis. In The Sage handbook of qualitative research in psychology (pp. 17-37). London: Sage.
The World Bank. (2018). Improving teaching and learning in Indonesia. https://www.worldbank.org/en/country/indonesia/brief/impro ving-teaching-and-learning-in-indonesia.

The World Bank. (2019). The promise of education in Indonesia. http://documents.worldbank.org/curated/en/126641574095155 348/Highlights.

TPD@ Scale Coalition. (2019). Primer: Quality education for all though empowered and effective teachers. https://tpdatscalecoali tion.org/wp-content/uploads/2019/03/TPD-at-Scale-Coalition-forthe-Global-South-PRIMER-updated-26-Mar-2019.pdf.

TPD@ Scale Indonesia. (2019). Teacher learning centre. https://tpdat scalecoalition.org/portfolio/tpdscale-indonesia/.

UNESCO. (2015). Education for all 2000-2015: Achievements and challenges (EFA global monitoring report). Paris: UNESCO. https://en.unesco.org/gem-report/report/2015/education-all-20002015-achievements-and-challenges.

UNESCO. (2020). Global education monitoring report: Education progress. Paris: UNESCO. https://www.education-progress.org/ en/articles/quality/.

Vygotsky, L. S. (1980). Mind in society: The development of higher psychological processes. Cambridge, MA: Harvard university press.

Publisher's Note Springer Nature remains neutral with regard to jurisdictional claims in published maps and institutional affiliations. 